\title{
Molecular Prevalence of Cryptosporidium spp. in Breeding Kennel Dogs
}

\author{
Naoyuki Itoh*, Hazuki Tanaka, Yuko lijima, Satoshi Kameshima, Yuya Kimura \\ Laboratory of Small Animal Internal Medicine, School of Veterinary Medicine, Kitasato University, Towada, Aomori, Japan
}

\begin{abstract}
Cryptosporidium is a common intestinal protozoan that can lead to diarrhea in humans and dogs. The predominant species of infection are C. hominis and C. parvum in humans, and C. canis in dogs. However, C. canis can infect immunocompromised humans. Considering the close contact with humans, dogs have the potential to be reservoirs for human cryptosporidiosis. Breeding kennels are the major supply source of puppies for pet shops. The present study is to determine the molecular prevalence and characteristics of Cryptosporidium spp. found in breeding kennel dogs. A total of 314 fecal samples were collected from young and adult dogs kept in 5 breeding kennels. A polymerase chain reaction targeting the small subunit rRNA gene was employed for the detection of Cryptosporidium spp. To determine the species, the DNA sequences were compared to GenBank data. Overall, $21.0 \%$ of the fecal samples were positive for Cryptosporidium spp. infection. Cryptosporidium spp. was detected in all 5 facilities. A sequencing analysis demonstrated that all isolates shared $99-100 \%$ similarity with C. canis. The results suggest that Cryptosporidium spp. infection is present at a high-level in breeding kennel dogs. However, because dominant species in this survey was $C$. canis, the importance of breeding kennel dogs as reservoirs for Cryptosporidium spp. transmission to humans is likely to be low in Japan.
\end{abstract}

Key words: Cryptosporidium spp., Cryptosporidium canis, dog, breeding kennel

Cryptosporidium is a common intestinal protozoan in many mammals, including humans and dogs, with a recognized potential to cause pathogen digestive tract obstruction in hosts [1-3]. The genus Cryptosporidium comprises more than 20 different species and at least 30 genotypes [3-5]. It was previously thought that each Cryptosporidium spp. had a narrow host range and was adapted to a specific animal or group of closely related animals [5]. For example, C. hominis and C. canis are apparently adapted to humans and dogs, respectively $[3,4]$. However, recently, it was demonstrated that some Cryptosporidium spp., such as C. parvum and C. muris, possess a broad range of hosts beyond the known animal species; therefore, they are zoonotic species $[4,5]$. Although there is no doubt that $C$. hominis and $C$. parrum predominantly infect humans and that C. canis predominantly infects dogs, C. canis and $C$. parvum have been isolated from both hosts $[4,5]$. Thus, $C$. canis can infect humans and dogs. Considering the close contact

\footnotetext{
- Received 26 December 2018, revised 27 February 2019, accepted 27 February 2019. *Corresponding author (naoitoh@vmas.kitasato-u.ac.jp) (C) 2019, Korean Society for Parasitology and Tropical Medicine This is an Open Access article distributed under the terms of the Creative Commons Attribution Non-Commercial License (http://creativecommons.org/licenses/by-nc/4.0) which permits unrestricted non-commercial use, distribution, and reproduction in any medium, provided the original work is properly cited.
}

dogs have with humans, dogs have the potential to be reservoirs for human cryptosporidiosis. Immunocompromised individuals, such as those infected with HIV, are at especially high risk for $C$. canis infection $[2,5]$. In Japan, the population of suspected immunocompromised individuals is growing because of an increasing elderly population and the increasing incidence of cancer.

The authors have previously determined the molecular prevalence and characteristics of the Cryptosporidium spp. in private household dogs and pet shop puppies and have demonstrated that pet shop puppies have a high-level prevalence of C. canis infection without exhibiting clinical signs [6]. Therefore, the present hypothesis that Cryptosporidium spp. will be detected at high-level prevalence in puppies/young dogs living in breeding kennel is logical, because the breeding kennels are the major source of puppies supplied to pet shops. Nevertheless, there is insufficient available data regarding the prevalence of Cryptosporidium spp. infection in breeding kennel dogs (young and adult); no such data exist in Japan [7-9].

The aim of the present study is to determine the molecular prevalence and characteristics of Cryptosporidium spp. in breeding kennel dogs, including an analysis of some factors such as dog age, so as to evaluate the risk of zoonotic transmission 
from breeding kennel dogs to humans.

Between August 2014 and July 2017, a total of 314 fresh voided fecal samples were randomly collected on a single occasion from dogs (aged 2 month-11 years, 85 males and 229 females) kept in 5 breeding kennels (A-E), located in the prefectures of Miyagi (A; $n=25)$, Niigata (B; $n=48)$, Gunma (C; $\mathrm{n}=87)$, Shizuoka ( $\mathrm{D} ; \mathrm{n}=31)$, and Aichi $(\mathrm{E} ; \mathrm{n}=123)$, in east Japan. All breeding kennel managers granted permission to include their dogs in the examination and donated fecal samples. The samples were collected immediately after natural defecation and were stored at $4^{\circ} \mathrm{C}$ prior to DNA extraction, which occurred within 3 days of collection.

The oocysts of Cryptosporidium spp. were separated using a sucrose gradient concentration method with a specific gravity of 1.26, and DNA extraction from oocysts was performed using a QIAamp DNA Mini Kit (QIAGEN GmbH, Hilden, Germany) according to the manufacturer's instructions. The DNA samples were stored at $-20^{\circ} \mathrm{C}$ prior to analysis.

Two-step nested polymerase chain reaction (PCR) targeting the small subunit (SSU) rRNA gene was employed for the detection of Cryptosporidium spp. For the first step reaction, the forward primer (5'-TTCTAGAGCTAATACATGCG-3') and the reverse primer ( $5^{\prime}$-CCCATTTCCTTCGAAACAGGA- $\left.3^{\prime}\right)$ were used to amplify a DNA fragment of approximately 1,325 bp. For the second step reaction, the forward primer (5'-GGAAGG GTTGTATTTATTAGATAAAG-3') and the reverse primer (5'-AA GGAGTAAGGAACAACCTCCA-3') were used to amplify a fragment of approximately $826 \mathrm{bp}$ [10].

For the first step reaction, the PCR mixture comprised $1 \times$ buffer containing $1.5 \mathrm{mM} \mathrm{MgCl}_{2}, 200 \mu \mathrm{M}$ of each dNTP, $0.5 \mu \mathrm{M}$ of each primer, 1.25 units of GoTaq DNA polymerase (Promega Corporation, Madison, Wisconsin, USA), and $2.0 \mu \mathrm{l}$ of template DNA in a total reaction volume of $25 \mu$ l. For the second step reaction, the PCR mixture was the same as for the first step reaction, except the amplicons from the primary PCR were used as templates. The first-step PCR was performed as follows: after an initial denaturation step of $3 \mathrm{~min}$ at $95^{\circ} \mathrm{C}$, 35 cycles, which each consist of $45 \mathrm{sec}$ at $95^{\circ} \mathrm{C}, 45 \mathrm{sec}$ at $59^{\circ} \mathrm{C}$ and $1 \mathrm{~min}$ at $72^{\circ} \mathrm{C}$, were performed, followed by a final extension of $5 \mathrm{~min}$ at $72^{\circ} \mathrm{C}$. The second-step PCR condition was performed as follows: after an initial denaturation step of $3 \mathrm{~min}$ at $95^{\circ} \mathrm{C}, 35$ cycles, which each consist of $30 \mathrm{sec}$ at $95^{\circ} \mathrm{C}, 1 \mathrm{~min}$ at $58^{\circ} \mathrm{C}$ and $1 \mathrm{~min}$ at $72^{\circ} \mathrm{C}$, were performed, followed by a final extension of $5 \mathrm{~min}$ at $72^{\circ} \mathrm{C}$.

All second-step PCR products were identified by electropho- resis on 1.5\% agarose gels. The specific DNA fragments (approximately $826 \mathrm{bp}$ ) were confirmed by alternative ethidium bromide staining and visualization under UV light using a transilluminator.

Second-step PCR amplicons of the predicted size were purified using a QIAquick Gel Extraction kit (QIAGEN GmbH, Hilden, Germany) and were sequenced with the second-step primer set. Sequences were analyzed by a commercial laboratory (FASMAC Co., Ltd., Kanagawa, Japan).

Sequence alignment and compilation were performed using the MEGA 6.06 program (www.megasoftware.net). To determine the species of Cryptosporidium, the DNA sequences were compared to GenBank sequences of Cryptosporidium spp. by BLAST searches (http://www.ncbi.nlm.nih.gov/). The similarity between the isolated and reference sequences was determined based on the degree of sequence identity.

The data were stratified according to age group ( $<1$-year-old vs $\geq 1$-year-old), fecal condition (normal vs soft/diarrhea) and the breeding kennel. Data were analyzed statistically using Fisher's exact probability test, with values of $P<0.05$ considered significant.

Overall, of the 314 breeding kennel dogs, 66 animals (21.0\%) were positive for Cryptosporidium spp. infection. According to age group, the prevalence of Cryptosporidium spp. in $<1$-year-old dogs $(45.0 \%)$ was significantly $(P<0.001)$ higher than that in $\geq 1$-year-old dogs (17.5\%) (Table 1). No significant difference was observed in fecal condition (normal: $20.7 \%$ vs soft/diarrhea: $23.3 \%$ ). Cryptosporidium spp. infection was determined in all breeding kennel facilities, ranging from

Table 1. Prevalence of Cryptosporidium species infection in breeding kennel dogs

\begin{tabular}{lcccc}
\hline & $\begin{array}{c}\text { Examined } \\
\text { No. }\end{array}$ & $\begin{array}{c}\text { Positive } \\
\text { No. }\end{array}$ & $\begin{array}{c}\text { Prevalence } \\
(\%)\end{array}$ & P-value \\
\hline Overall & 314 & 66 & 21.00 & - \\
$\begin{array}{l}\text { Age } \\
\quad \text { 1-year-old }\end{array}$ & 40 & 18 & 45.00 & $<0.001$ \\
$\quad \begin{array}{l}\text { 1-year-old } \\
\text { Fecal condition }\end{array}$ & 274 & 48 & 17.50 & - \\
$\quad$ Normal & 271 & 56 & 20.70 & - \\
$\quad$ Soft/Diarrhea & 43 & 10 & 23.30 & NS \\
Breeding kennel & & & & \\
A & 25 & 2 & 8.00 & - \\
B & 48 & 10 & 20.80 & NS \\
C & 87 & 17 & 19.50 & NS \\
D & 31 & 5 & 16.10 & NS \\
E & 123 & 32 & 26.00 & NS \\
\hline
\end{tabular}

NS, not significant. 
$8.0 \%$ to $26.0 \%$ prevalence, with no significant differences observed between kennels.

A sequencing analysis of the SSU rRNA gene fragments demonstrated that all 66 PCR-positive amplicons shared 99-100\% similarity with the sequences of $C$. canis (accession numbers: KR999987, KR999984, JN543380, MF589918, KF516542 and EU754826) retrieved from the GenBank database.

The present study is the first report describing the molecular prevalence of Cryptosporidium spp. infection in breeding kennel dogs in Japan. The results of the study support the authors' hypothesis because Cryptosporidium spp. infection was detected at markedly high prevalence (45.0\%) in young dogs in breeding kennels. In addition, the prevalence of infection was also high in adult dogs (17.5\%). In contrast, previous recent studies have reported low prevalences of Cryptosporidium spp. infection in breeding kennel dogs, such as 5.0\% in Italy [7], $0 \%$ in Belgium [8] and $7.0 \%$ in China [9]. The cause of low infection prevalence in those previous cases is not known. A significantly highlevel detection of intestinal protozoans, such as Giardia and Cystoisospora, has been reported in breeding kennel dogs $[8,11]$. Additionally, a high prevalence of Cryptosporidium spp. infection has been detected in pet shop puppies [6], most of which were likely derived from breeding kennels. However, the authors cannot simply compare the results of the present study to those of previous studies due to differences in dog's ages, study regions, and examination methods. Therefore, the most important highlight here is the suggestion of high-level Cryptosporidium spp. infection in not only young dogs, but also adult animals kept in breeding kennels.

A high-level of Cryptosporidium spp. infection in younger dogs, including puppies, has previously been documented $[6,12,13]$. Although the role of immune responses against Cryptosporidium spp. infections is unknown in dogs, the immature immune system of young dogs is suspected to be a major factor for high-level infection. Because it is commonly accepted that both innate and adaptive immune responses are important for controlling Cryptosporidium spp. infections [2,14, 15], an immature immune system is indicated in young dogs $[16,17]$. Additionally, the stressful situations presented in breeding kennels, such as frequent contact with other animals in a limited space, is also a significant factor for high prevalence due to the induction of immunosuppressive status [18]. Simultaneously, the stressful situations in breeding kennels are likely to be factors in the high prevalence of infection in adult dogs. In the present study, the prevalence of infection in $\geq 1$-year-old male dogs (15.4\%; 12/78 dogs) was roughly the same as that in females in the same age group (18.4\%; 36/196 dogs). Lastly, sanitary management and environmental conditions were not evaluated here, but environmental contamination via Cryptosporidium oocysts is considered the most important factor for high prevalence in breeding kennel dogs. It has been demonstrated that the Cryptosporidium oocyst is resistant against common disinfectants and can survive in environments for duration of at least several months [2,19]; thus, it is very difficult to eliminate Cryptosporidium oocysts in breeding kennel facilities. In all breeding kennels, the above factors contribute to maintain a high-level of Cryptosporidium spp. infection, and frequent reinfection is suspected. As with results from related previous studies, there was no correlation between the detection of Cryptosporidium spp. in dogs and the fecal conditions $[6,20]$. The coinfection with other intestinal protozoa such as Giardia spp. is suggested as a factor of inducing clinical signs [1].

The sequencing data demonstrates the dominancy of $C$. $c a-$ nis in breeding kennel dogs in Japan. It is easy to understand this result, because C. canis is a dog-adapted species $[3,4]$. Therefore, the importance of breeding kennel dogs as reservoirs for Cryptosporidium spp. transmission to humans is likely to be low in Japan, since the predominant species for human cryptosporidiosis are C. hominis and C. parnum. However, we should remember that immunocompromised humans have a potential risk for infection of C. canis $[2,5]$.

\section{CONFLICT OF INTEREST}

On behalf of all authors, the corresponding author states that there is no conflict of interest.

\section{REFERENCES}

1. Scorza S, Tangtrongsup S. Update on the diagnosis and management of Cryptosporidium spp infections in dogs and cats. Top Companion Anim Med 2010; 25: 163-169.

2. Bouzid M, Hunter PR, Chalmers RM, Tyler KM. Cryptosporidium pathogenicity and virulence. Clin Microbiol Rev 2013; 26: 115134.

3. Ryan U, Zahedi A, Paparini A. Cryptosporidium in humans and animals--a one health approach to prophylaxis. Parasite Immunol 2016; 38: 535-547.

4. Feng Y, Ryan UM, Xiao L. Genetic diversity and population structure of Cryptosporidium. Trends Parasitol 2018; 34: 997-1011.

5. Khan A, Shaik JS, Grigg ME. Genomics and molecular epidemi- 
ology of Cryptosporidium species. Acta Trop 2018; 184: 1-14.

6. Itoh N, Oohashi Y, Ichikawa-Seki M, Itagaki T, Ito Y, Saeki H, Kanai K, Chikazawa S, Hori Y, Hoshi F, Higuchi S. Molecular detection and characterization of Cryptosporidium species in household dogs, pet shop puppies, and dogs kept in a school of veterinary nursing in Japan. Vet Parasitol 2014; 200: 284-288.

7. Giangaspero A, Iorio R, Paoletti B, Traversa D, Capelli G. Molecular evidence for Cryptosporidium infection in dogs in Central Italy. Parasitol Res 2006; 99: 297-299.

8. Claerebout E, Casaert S, Dalemans AC, De Wilde N, Levecke B, Vercruysse J, Geurden T. Giardia and other intestinal parasites in different dog populations in Northern Belgium. Vet Parasitol 2009; 161: 41-46.

9. Jian F, Qi M, He X, Wang R, Zhang S, Dong H, Zhang L. Occurrence and molecular characterization of Cryptosporidium in dogs Henna Province, China. BMC Vet Res 2014; 10: 26.

10. Xiao L, Morgan UM, Limor J, Escalante A, Arrowood M, Shulaw W, Thompson RCA, Fayer R, Lal AA. Genetic diversity within Cryptosporidium parvum and related Cryptosporidium species. Appl Environ Microbiol 1999; 65: 3386-3391.

11. Itoh N, Kanai K, Kimura Y, Chikazawa S, Hori Y, Hoshi F. Prevalence of intestinal parasites in breeding kennel dogs in Japan. Parasitol Res 2015; 114: 1221-1224.

12. Hamnes IS, Gjerde BK, Robertson LJ. A longitudinal study on the occurrence of Cryptosporidium and Giardia in dogs during their first year life. Acta Vet Scand 2007; 49: 22.
13. Uehlinger FD, Greenwood SJ, McClure JT, Conboy G, O'Handley R, Barkema HW. Zoonotic potential of Giardia duodenalis and Cryptosporidium spp. and prevalence of intestinal parasites in young dogs from different populations on Prince Edward Island, Canada. Vet Parasitol 2013; 196: 509-514.

14. Petry F, Jakobi V, Tessema TS. Host immune response to Cryptosporidium parum infection. Exp Parasitol 2010; 126: 304-309.

15. McDonald V, Korbel DS, Barakat FM, Choudhry N, Petry F. Innate immune responses against Cryptosporidium parrum infection. Parasite Immunol 2013; 35: 55-64.

16. Faldyna M, Levá L, Knötigová $\mathrm{P}$, Toman M. Lymphocyte subsets in peripheral blood of dogs--a flow cytometric study. Vet Immunol Immunopathol 2001; 82: 23-37.

17. Day MJ. Immune system development in the dog and cat. J Comp Pathol 2007; 137 (suppl): 10-15.

18. Powell ND, Allen RG, Hufnagle AR, Sheridan JF, Bailey MT. Stressor-induced alterations of adaptive immunity to vaccination and viral pathogens. Immunol Allergy Clin N Am 2011; 31: 69-79.

19. Sunnotel O, Lowery CJ, Moore JE, Dooley JSG, Xiao L, Millar BC, Rooney PJ, Snelling WJ. Cryptosporidium. Lett Appl Microbiol 2006; 43: 7-16.

20. Wang A, Ruch-Gallie R, Scorza V, Lin P, Lappin MR. Prevalence of Giardia and Cryptosporidium species in dog park attending dogs compared to non-dog park attending dogs in one region of Colorado. Vet Parasitol 2012; 184: 335-340. 